\title{
Fostering Empathic Skills in Mainstream Public School Pupils: Efficacy Assessment of the EPaN Empathy Training Program
}

\author{
Sebastian Ludwig Hirn ${ }^{1}$, Regina Weißmann ${ }^{1}$, Christof Zoelch ${ }^{1}$, Joachim Thomas ${ }^{1}$ \\ ${ }^{1}$ Department of Psychological Diagnostics and Intervention Psychology and School Psychology at Catholic University \\ of Eichstätt-Ingolstadt, Bavaria, Germany \\ Correspondence: Sebastian L. Hirn, Department of Psychological Diagnostics and Intervention Psychology and School \\ Psychology at Catholic University of Eichstätt-Ingolstadt, Bavaria, Germany.
}

Received: December 1, 2019

Accepted: January 15, $2020 \quad$ Online Published: January 17, 2020

doi:10.11114/jets.v8i3.4689

URL: https://doi.org/10.11114/jets.v8i3.4689

\begin{abstract}
Empathic skills are called for in every social interaction, but there are few evidence-based programs in the mainstream public school sector exclusively dedicated to fostering the empathic sub-components of recognition of emotions, emotional perspective taking and affective responsiveness in pupils. The EPaN program is based on the latest scientific knowledge and best practices that can be taught in the classroom.

In the course of eight school weeks, using a pre-post-test design we studied the effectiveness of an empathy training program $(E P a N)$ in nine classes with a total of 123 mainstream public school pupils aged 11.2 to 15.2 years, divided into intervention groups that were assigned a total of 24 exercises of 15 to 40 minutes duration and control groups that followed the regular lesson plan.

After the training, variance analysis showed a significant improvement in the empathic sub-capacities for recognition of emotion, emotional perspective taking and affective responsiveness in the intervention groups compared to the control groups. These results are examined in light of their importance and adaptability of the EPaN program to educational practice.
\end{abstract}

Keywords: empathy fostering, training program, empathic skills, mainstream public school, evaluation study

\section{Introduction}

Social skills as available actional, cognitive and emotional behaviors (Döpfner, 1989; Hinsch \& Pfingsten, 2015) count among the important key competencies in the world of work (Maier \& Rappensberger, 1999). They are cited in the same vein not only in the school sector - as in the Supreme Educational Objectives set out in Article 131 of the Bavarian Constitution and in the Law on Education and Training (BayEUG) in Article 1 dealing with the educational and training mission, as well as in Article 2 of the BayEUG addressing the tasks of schools - but also worldwide (Elias, 2006). It follows that social skills form the basis for social learning as an educational principle (ISB, 2015). To pave the way for successful occupational integration and development, especially given the current changes impacting the student population, Brattig (2013) sees an even greater need for promoting social competence early on in the school context (Fath, 2011).

Socially competent behaviors help young people achieve their own goals in a social interaction while simultaneously respecting the interests of the interaction partners. Appropriate, effective and cooperative behavior in adolescence thus arises from balancing own goal-seeking with adapting to the expectations of the interaction partner. Models of social information processing are particularly well-suited for capturing specific sub-components of social competence (action evaluation, consequence anticipation, goal attainment, consequence expectations) as situation-dependent, changeable capabilities and proficiencies in social interactions (Döpfner, 1989; Thomas, Jänsch, \& Niedermaier, 2006). In each step of these sequentially successive phases, cognitive factors as well as emotions at times function as integral components of empathy (Crick \& Dodge, 1994; Döpfner, 1989). In psychological research, empathy connotes an often experimentally verified relationship to prosocial behavior in the process (Eisenberg, 1987, 2000; Paciello et al. 2013; Strayer \& Roberts, 2004). However, two traditions in empathy research either regard the affective and cognitive empathic processes as distinct, or, in a newer line of research, regard them as firmly linked (Decety \& Jackson, 2006). Cognitive developments in adolescence accelerate due to biological changes in the brain, thus helping youngsters progressively exploit 
environmental and personality areas, structure overviews, adopt meta-perspectives and understand networking sooner (Demetriou, Christou, Spanoudis, \& Platsidou, 2002), which ultimately boosts the growth of emotional capacities. The starting point for conceiving a potential new training method for fostering empathy thus involves shifting the focus to malleable sub-components, i.e., learnable capabilities and proficiencies, which, with practice, can be developed early in life (Roth, Altmann, \& Schönefeld, 2016).

\subsection{Theoretical Foundations of the EPaN Program}

In the extended and integrated working model of social information processing by Thomas, Jänsch, and Niedermaier (2006), cognitive factors join with the influences of emotional components (Adolphs \& Damasio, 2000; Lemerise \& Arsenio, 2000) to form the basis for human empathy, the main components of which can be found primarily in process models (Decety \& Jackson, 2004, 2006; Shamay-Tsoory, 2009).

In setting up the EPaN program, we used the definitional approximation by Derntl and colleagues (2010). They describe empathy as a "multidimensional construct" that "requires the ability to perceive, understand and feel the emotional states of others" (p. 2). Three core components of the empathy construct can be derived from understanding different approaches (Decety \& Jackson, 2004; Decety \& Lamm, 2006; Decety \& Moriguchi, 2007). The core components are:

1. Recognition of emotions: the capability to distinguish spoken from behavioral expressions of own and others' emotions by recognizing emotive facial expressions.

2. Emotional perspective taking: the capability of seeing things from another's point of view, regardless of the subjective approach.

3. Affective responsiveness: this in turn is the capability of sharing the emotional states of others. The observer becomes aware of the simulated feeling and not of the own emotion.

Hirn, Thomas and Zoelch (2018) shed a more precise light on the positive correlations between the selected social competence dimensions that they extracted from the extended model of social information processing by Thomas and colleagues (2006) and the core components of empathy. The investigated empathic skill measures in the process turn out be interdependent, dynamic components that clearly correlate positively with the dimensions of social competence and, moreover, influence them directly and indirectly (Hirn et al., 2018). Especially the cognitive empathy component emotional perspective taking affects all social competence dimensions. Significantly, the insights drawn from the findings by Hirn and colleagues (2018) also indicate that the focus should be on the interacting empathy components when it comes to structuring the substantive training method in schools - since the cognitive aspects of proficiency as upstream components in recognizing one's own emotions and those of others in particular exert varying degrees of influence on the socially-competent behavior decision. Empathic skills can in fact be learned, fostered and even trained as such (Cierpka, 2011; Decety \& Lamm, 2006) when both affective and cognitive phenomena of empathy are incorporated in the program design (Nerdrum \& Ronnestad, 2003).

\subsection{Structure and Content of the EPaN Program}

The EPaN program, based on the current research findings of Hirn and colleagues (2018) with allowances made for ageand development-related skills and learning requirements, is basically structured as these three toolkits: (1) recognition of exmotions (2) perspective taking and (3) (affective) responsiveness (i.e., Nacherleben in German). The initial letters of the toolkits make up the $E P a N$ acronym. Table 1 provides an $E P a N$ program overview of the individual toolkit contents with a thumbnail goal description for each of the sub-exercises. 
Table 1. EPaN program overview with thumbnail description of the sub-exercise goals

\begin{tabular}{|c|c|}
\hline \multicolumn{2}{|c|}{ Toolkit 1: Recognition of emotions } \\
\hline Module 1:1 My Feelings and Your Feelings & Module 1.2: Recognize Other Feelings \\
\hline Part A: Walk on the beach & Part A: Bandleader \\
\hline Goal: Being more aware of inner feelings, thoughts, and & Goal: Consciously perceiving facial expressions, \\
\hline physical sensations & and differentiating body perceptions \\
\hline Part B: Two aspects of my emotional world & Part B: Picture phone \\
\hline Goal: Perceiving and distinguishing feelings & Goal: Expressing emotions with mouth and eyes \\
\hline Part C: "No" and "Yes" & Part C: On stage \\
\hline Goal: Cultivating awareness of pre-linguistic and & Goal: Understanding emotions physically without \\
\hline paralingual aspects & voicing them \\
\hline Part D: Short message & Part D: Gestures of farewell \\
\hline Goal: Positive trait attributions; & Goal: Making farewell gestures with appropriate \\
\hline strengthening the individual personality & facial expressions and gestures \\
\hline
\end{tabular}

Toolkit 2: Emotional perspective taking

Module 2.1: My perspective and your perspective

Part A: Magic box

Goal: Consciously expressing and describing postures and feelings

Part B: Do you understand me?

Goal: Understanding your own perspective as Goal: Progressively improving understanding of (subjectively) seen by others

Part C: Forming statues

Goal: Perceiving and absorbing perspectives in a differentiated way while "doing"

Part D: Talk about

Goal: Appropriately making your own views explicit and taking needs of others into account in conversation

Module 2.2: Taking different perspectives

Part A: Matched face

Goal: Seeing things from other perspectives and determining how to think and feel about them

Part B: False-belief task

complex issues

Part C: Understanding roles

Goal: Recognizing and understanding the beliefs of other people

Part D: (Postcard) greetings

Goal: Becoming more consciously aware of own strengths; acknowledging positive attributes.

\section{Toolkit 3: Affective responsiveness}

Module 3.1: My experience and your experience Module 3.2: Feeling different

Part A: A hike with full luggage Part A: Image in motion

Goal: Being aware of inner thoughts and feelings and distancing yourself from them

Goal: Accepting and eliciting others' inputs to expand own image contents

Part B: Mirror or shadow

Part B: What does the person feel?

Goal: Consciously reliving shared movements

Goal: Imitating emotional states spontaneously; purposefully observing mimicry and gestures

Part C: Emotional poles

Part C: Wax figures

Goal: Consciously tracing deformed conflicting feelings

Goal: Empathizing with and recreating situations and comparing them with others' mental states

Part D: Emotional poles in motion Part D: In the circle of trust

Goal: Increasingly experiencing own emotional Goal: Providing a safe environment and creating an polarities and those set by others in a purposeful way experience of trust 
The materials for the toolkit exercises furnished to the trainers in tabular, manualized and even digitized form are completely ready to use. The toolkits can be flexibly selected for processing in whatever order desired. However, starting with toolkit 1 is recommended, because sub-areas from toolkits 2 and 3 refer back to knowledge developed in it. Since a true empathic response requires in particular the ability to distinguish between the origin of a feeling in oneself and in the other (Decety \& Lamm, 2006), conceptually this suggests therefore that each toolkit should be divided into a module centered on the level of the individual self and one centered on the level of the other.

Each module area, in turn, with its often repetitive but quite varied exercises should promote the development and strengthening of trainable empathic sub-skills. Completing one module per school week at the rate of one exercise per day would be optimal. The 24 different exercises range in length from about 15 to 40 minutes and thus take up only a fraction of a class period and involve social forms established in them.

\subsection{Deriving the Evaluation Objectives}

In general, the effectiveness of training and intervention programs specifically designed to foster empathy in secondary school-age children has been documented, despite inconsistent work definitions in the relevant evaluation studies. This is accomplished by choosing varied methods to generate a positive outcome of gains in empathic capacities, in levels of empathy, or even in prosocial behavior (Haep, Steins, \& Wilde, 2014; Haynes \& Avery, 1979; Kipper \& Ben-Elvy, 1979; Manger, Eikeland, \& Asbjornsen, 2001; Pecukonis, 1990). Empathy training is often one of several facets in broader programs (Berhofer, Gonja, \& Oberlechner, 2008; McMahon \& Washburn, 2003; Schultze-Krumbholz, Zagorscak, Wölfer, \& Scheithauer, 2014), which can complicate its integration into regular classes from a school organizational point of view. In addition, Yanagida, Strohmeier and Spiel (2019) do not rule out a potential impact of empathic skills as a universal upstream means for ensuring the success of their internationally implemented social competence program (ViSC).

In the German-speaking countries, however, as yet no comparable evaluation studies, adapted to the partial empathic capabilities of children and adolescents in the mainstream public school sector under discussion, are to be found that explicitly investigate the exercises conceptualized here. For the group of mainstream public school pupils, supplemental evaluation studies are of such great importance because it cannot be assumed that the training measures used by special cohorts from the part-American, part-German-speaking realm are directly transferable to this type of school. Furthermore, given their long gestation period, the didactic methods and material specifications of the available programs are often no longer suitable for implementation in classrooms under the school sector's current skill-oriented curricula. The didactic content reduction due to the shift in the pupil clientele also renders the use of older programs problematic. This immediately raises the interesting question if deploying the EPaN program to foster recognition of emotions, emotional perspective taking, and affective responsiveness in mainstream public school students as part of regular lesson plans is even feasible. This led to derivation of the following evaluation goals:

1. The mainstream school pupils trained in the EPaN program are to be markedly better at recognition of emotions immediately after receiving the training than prior to it, compared with the pupils in the control groups which attended regular classes.

2. Compared with the control group in regular classes, the mainstream public school pupils immediately after training in the EPaN program are to show marked improvement in their capacity for emotional perspective taking.

3. The mainstream school pupils trained in the intervention group immediately after their training must demonstrate marked improvement in their capacity for affective responsiveness as opposed to pupils in the control group that received only regular classroom instruction.

\section{Method}

\subsection{Sample and Study Design}

A total of 123 pupils $\left(\mathrm{M}_{\text {age }}=13.10\right.$ years, $\left.S D=2.1\right)$ from nine classes in the sixth and eighth grades of rural and urban mainstream public schools took part in the study, which lasted from February to May 2019.86 students were male (69.9\%) and 37 female (30.1\%). The gender distribution of the subjects corresponded to the natural composition of mainstream public school classes. At the time of the training, 34 pupils $(27.6 \%)$ were 11 years old, 32 students $(26 \%) 12$ years old, 21 students (17.1\%) 13 years old, 30 students (24.4\%) 14 years old and six students (4.9\%) were 15 years old. To test the effect of the EpaN program on the empathy components of the pupils, we chose a pre-post-test design. Participants were randomly distributed among the intervention groups $\left(N=72, n=24\right.$ were female and $n=48$ were male, $M_{\text {age }}=13.2$ years, $S D=1.13)$ and the control group $\left(N=51, n=13\right.$ were female and $n=38$ were male, $M_{\text {age }}=13.4$ years, $\left.S D=1.0\right)$. The parents were informed ahead of time and their active consent was obtained. The pretest two weeks before and the posttest about two weeks later consisted of a short version for all pupils to check the trainable empathy components. During the pre- and posttest, trained staff made sure that the participants could not influence each other in their response behavior. 
Following the pretest in February 2019, each intervention group worked on weekly exercises of 15 to 40 minutes duration each from the three $E P a N$ toolkits. After each toolkit, the test administrators evaluated key training characteristics observed during the intervention.

\subsection{Data Gathering Procedure}

For a valid capture of the empathy components, a short form of each instrument described below was employed for the pre- and post-test:

a) Recognition of emotion

This component was surveyed in the pre- and posttest using 19 context-free color photographs from the short form of the Vienna Emotion Recognition Tasks (Pawelak, 2004), which show one of the basic emotions (anger, fear, grief, disgust, joy) or a neutral expression on a Caucasian face. The pupils selected one of the six categories presented for each face under forced choice questioning. The intensity of the rating was marked on a six-point scale. The images were shown in a randomized sequence with no time constraints. The chosen standardized stimulus set depicting evoked emotional expressions of actors with consideration for gender, age, intensity and valence was taken from Gur and colleagues (2002). The material has previously been used successfully in several studies on the recognition of emotions (Derntl et al., 2008(a); Derntl et al., 2008(b); Derntl et al., 2009; Fizgerald et al., 2006; Habel et al., 2007; Hirn et al., 2018; Moser et al., 2007). Acceptable values for internal consistency could be calculated for short form $A(\alpha=.75)$ and short form $B(\alpha=.76)$.

\section{b) Emotional perspective taking}

Emotional perspective taking was also vetted during the pre- and posttest, once again using 19 color photographs each depicting two interacting Caucasians in everyday situations going through three situations each per basic emotion and neutral contexts. For the masked face, the students were asked to choose the correct one from two alternative responses based on the posture and mimic facial expressions of the interaction partner and then rate them on another six-point scale. The response stimuli were again taken from the faces database of Gur and colleagues (2002); the context-free staging this time came from Derntl and colleagues $(2009,2010)$. The randomly presented scenes were worked on without any time limit. Measurements of internal consistency yielded satisfactory values, with a Cronbach's $\alpha$ of .72 for short form A and .73 for short form $B$.

\section{c) Affective responsiveness}

The procedures for affective responsiveness each encompassed 19 short sentences for short forms $A$ and $B$ from the reallife world of children and adolescents that were neutral in terms of emotional content or induced one of the five basic emotions. The sentences were taken from Derntl and colleagues (2010), but adapted here to the school context. As answer format served a selection of evoked facial expressions from the stimulus material of Gur and colleagues (2002). The processing time was not a factor, the order of the stimuli was again random, and the rating was done on a six-point scale. Test forms $A$ and $B$ yielded acceptable Cronbach's $\alpha$ respectively of .88 and .79 in the internal consistencies.

To optimize the content and components of the EPaN program and to check the change in acceptance among the youths with a view to increasing the method's overall impact, the implementers during the interventions were verbally asked brief quantitative as well as qualitative questions. On a six-point scale, they evaluated key characteristics by Fries and Souvignier (2015) on the method's structure, the transfer of procedural knowledge, repetitive practice of specific tasks and on relevance to the recipients and target groups.

\subsection{Analysis}

The data was processed with SPSS Statistics 25 software. Potential empathy-fostering effects of the three dependent variables recognition of emotion, emotional perspective taking and affective responsiveness were investigated using variance analyses with measurement repetition. The trainer surveys conducted during the intervention were done descriptively.

\section{Results}

\subsection{Variance Analyses}

The empathy fostering effect of the three dependent variables recognition of emotion, emotional perspective taking, and affective responsiveness were investigated using variance analyses with repeat measurement, wherein the two-step repeated-measure factor time (in pretest and posttest) was treated as a within-subject variable, the group (control vs. intervention group) and the grade levels (6th and 8th grade) as between-subject factors and gender and age as covariates.

First, we will look at the results from the three-factor variance analysis for the dependent variables, then present the individual values for each.

The evaluation of the three-factorial variance analysis in Table 2 initially revealed a highly significant main effect of the 
group $\left[\mathrm{F}(1,122)=16.08 ; \mathrm{p}=.000\right.$, partial $\left.\eta^{2}=.12, N=123\right]$ and a highly significant main effect of time $[\mathrm{F}(1,122)=17.44 ;$ $\mathrm{p}=.000$, partial $\left.\eta^{2}=.13, N=123\right]$ with a high effect strength after Cohen (1992) of $f=.40$ and $f=.41$. As a result, the experimental groups overall improved significantly in terms of their empathic subcomponents during the study period. Furthermore, a highly significant interaction between group and time was observed $[\mathrm{F}(1,122)=15.68 ; \mathrm{p}=.000$, partial $\left.\eta^{2}=.26, N=123\right]$, with a corresponding strong effect according to Cohen (1992) of $f=.68$. This finding provides supporting evidence for the effectiveness of the empathic training method. The examination of the interaction via the time factor and the between-subject factors $\operatorname{sex}\left[\mathrm{F}(1,122)=3.09 ; \mathrm{p}=.082\right.$, partial $\left.\eta^{2}=.03, N=123\right]$, age $[\mathrm{F}(1,122)=.91$; $\mathrm{p}=.343$, partial $\left.\eta^{2}=.01, N=123\right]$ and grade level $\left[\mathrm{F}(1,122)=.03 ; \mathrm{p}=.856\right.$, partial $\left.\eta^{2}=.00, N=123\right]$ on the other hand did not yield any significance nor did the examination of each empathic subcomponent.

The separately observed individual effects of the dependent variables in the intervention groups are discussed in greater detail in the next step.

Table 2. Results of the variance analyses with repeat measurement based on the dependent variables recognition of emotions (ER), emotional perspective taking (PT) and affective recognition (AN)

\begin{tabular}{llllllll}
\hline $\begin{array}{l}\text { Source of the } \\
\text { Variation }\end{array}$ & Ss & $d f$ & $M s$ & $Q$ & $p$ & partial $\eta^{2}$ & $f$ \\
\hline
\end{tabular}

\section{Sum}

a) Main effects

- Group

- Time

$26.73 \quad 1$

26.73

16.08

.000

.12

.40

b) Interaction effect

Group x Time

6.79

6.79

17.44

.000

.13

.41

15.68

15.68

40.29

.000

.26

.68

ER

a) Main effects

- Group

$13.62 \quad 1 \quad 13.62$

26.12

.000

.18

.52

- Time

$\begin{array}{lll}2.69 & 1 & 2.69\end{array}$

7.37

.008

.06

.26

b) Interaction effect

Group x Time

4.76

1

4.76

13.02

.000

.10

.35

PT

a) Main effects

- Group

9.95

9.95

11.00

.001

.09

.33

- Time

$.74 \quad 1$

.74

2.04

.155 n.s.

.02

.14

b) Interaction effect

Group x Time

10.21

$1 \quad 10.21$

28.39

.000

.19

.54

\section{AN}

a) Main effects

$\begin{array}{llllllll}\text { - Group } & 9.37 & 1 & 9.37 & 6.30 & .013 & .05 & .23 \\ \text { - Time } & 1.39 & 1 & 1.39 & 3.99 & .048 & .03 & .18\end{array}$

b) Interaction effects

Group x Time

$2.73 \quad 1 \quad 2.73$

7.87

.006

$.06 \quad .26$

Notes: $\overline{\mathrm{SS}}=$ Sum of Squares; $\mathrm{df}=$ degrees of freedom; $\mathrm{Ms}=$ mean; square; $\mathrm{p}=\mathrm{p}$-values; partial $\eta^{2}=$ partial eta-squared; $f=$ effect size

a) Recognition of emotion (ER): A significant main effect of the measurement time point $[\mathrm{F}(1,71)=7.37 ; \mathrm{p}=.008$, partial $\left.\eta^{2}=.06, N=72\right]$ resulted with a mean effect strength of $f=.26$ and a significant main effect of the group $[\mathrm{F}(1,71)=26.12$; $\mathrm{p}=.000$, partial $\eta^{2}=.18, N=72$ ] with a strong effect of $f=.52$ after Cohen (1992) on the recognition of emotion dependent variables, which are qualified by a significant interaction between time and group $\left[\mathrm{F}(1,71)=13.02 ; \mathrm{p}=.000\right.$, partial $\eta^{2}$ 
$=.10, N=72]$. Overall, as shown in Figure 1, the intervention groups in the recognition of emotion component therefore showed significant improvement after empathy training $(M=4.11, S D=.69)$, compared to the start of training $(M=3.49$, $S D=.75)$. This is based on a mean effect strength after Cohen (1992) of $f=.35$. It contrasts with the absence of any significant performance gains in the control group either in the pretest $(M=3.38, S D=.72)$ or in the posttest $(M=3.65$, $S D=.69)$. Slightly higher initial values of the recognition of emotion component in the intervention group $(M=3.49)$ over the control group $(M=3.38)$ are associated with an increase in female test subjects and a slightly higher sample size in the training group (see Hall \& Matsumoto, 2004; Vasallo, Cooper, \& Douglas, 2009).

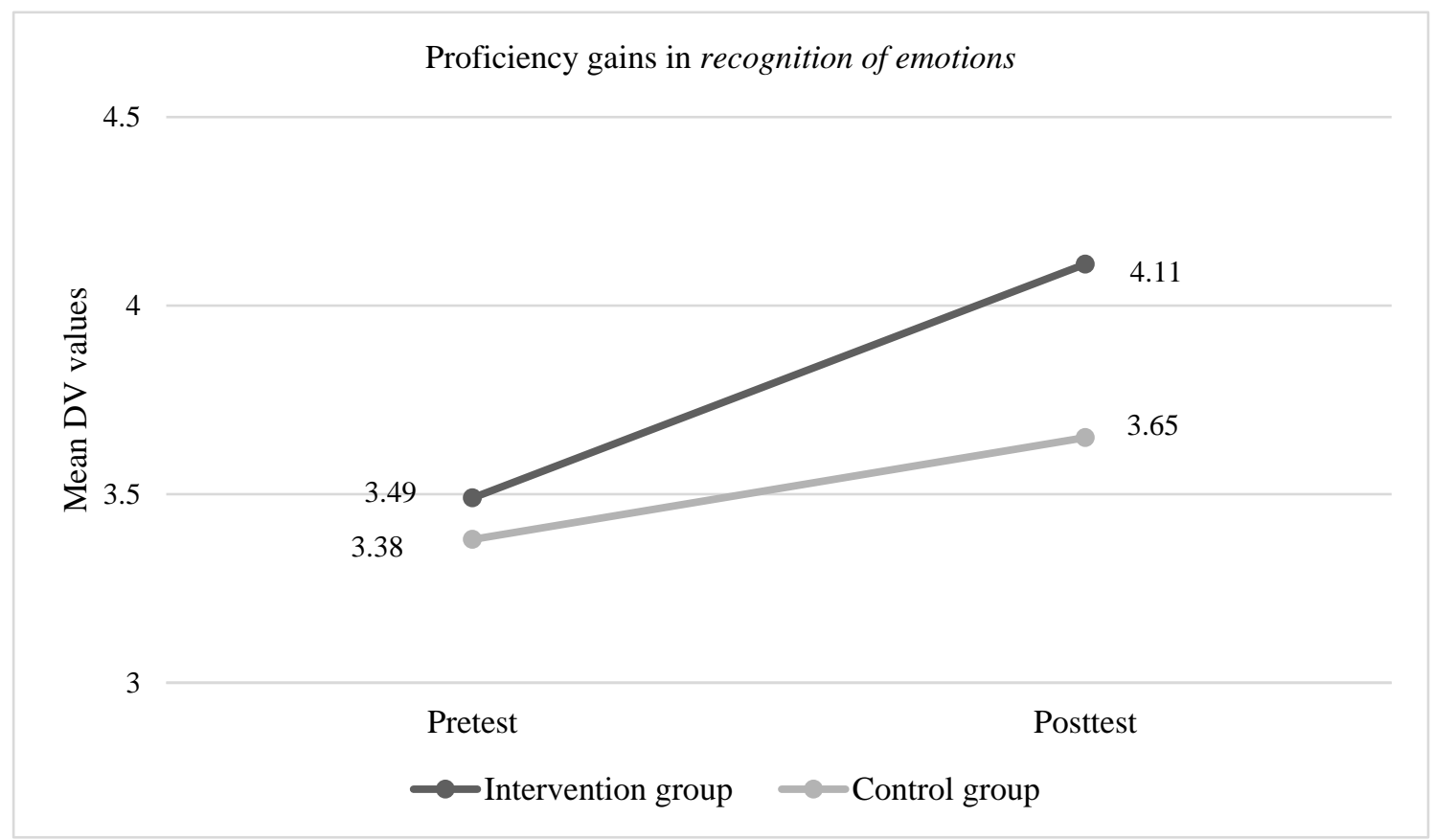

Figure 1. Dependent variable recognition of emotions - differences in proficiency gains of intervention group and control group

b) Emotional perspective taking (PT): The variance-analytical results on the emotional perspective taking dependent variable yielded significant empathy fostering effects. The significant main effect of the group $[\mathrm{F}(1,71)=11.00 ; \mathrm{p}=.001$, partial $\left.\eta^{2}=.09, N=72\right]$ is corroborated by a like interaction between time and group $[\mathrm{F}(1,71)=28.39 ; \mathrm{p}=.000, \mathrm{partial}$ $\left.\eta^{2}=.19, N=72\right]$ with a strong effect of $f=.54$ following Cohen (1992). Thus, in Figure 2, pupils trained in the $E P a N$ program achieved a post-intervention improvement $(M=4.36, S D=.84)$. The control group pupils without $E P a N$ empathy training $(M=3.87, S D=.86)$ scored only a slight increase in their emotional perspective taking skills over the pretest $(M$ $=3.67, S D=.94)$. However, this has no statistically significant effect. 


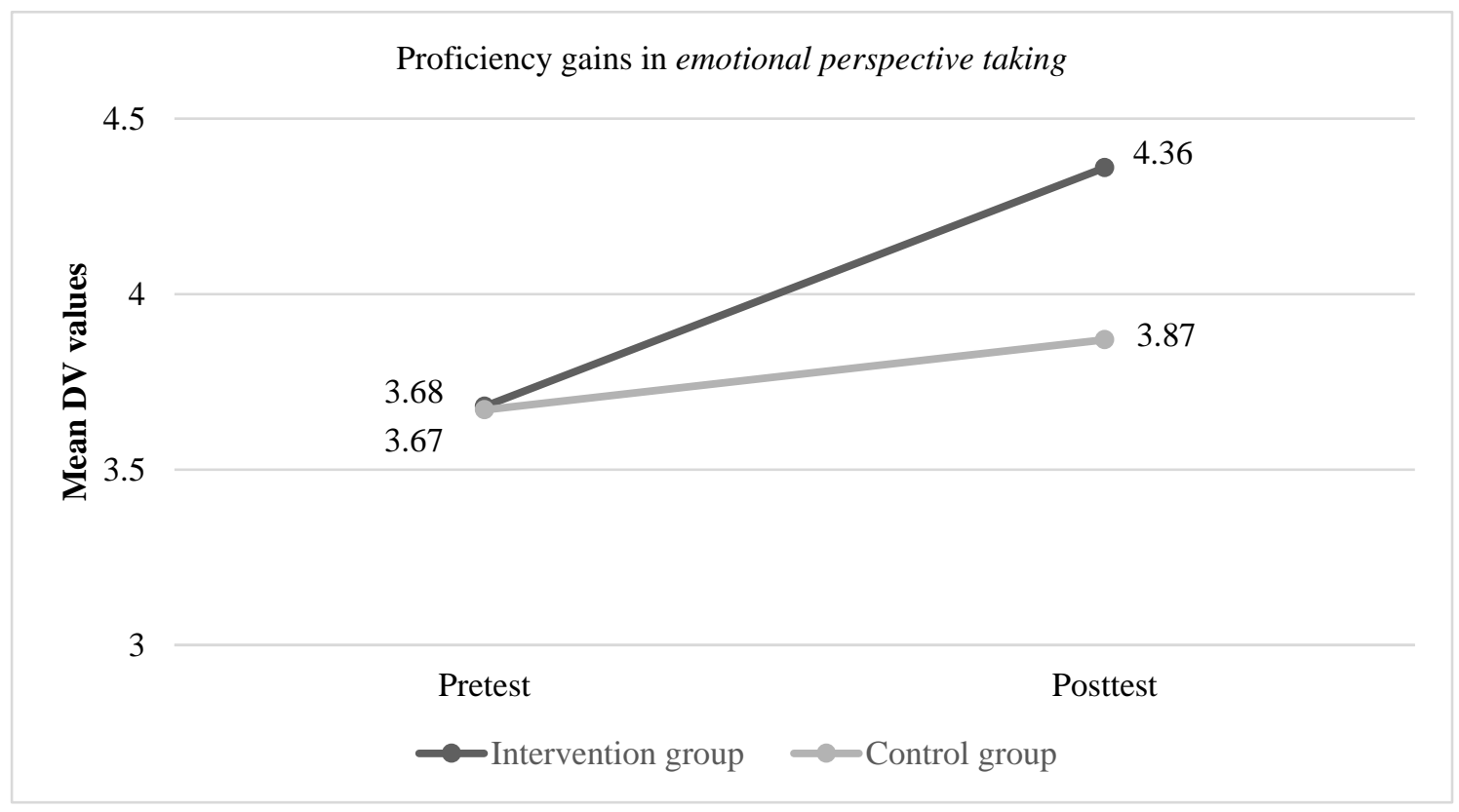

Figure 2. Dependent variable emotional perspective taking - differences in the proficiency gains of intervention group and control group

c) Affective responsiveness $(A N)$ : For the affective responsiveness dependent variable, the variance analysis once again demonstrated a significant main effect of time $\left[\mathrm{F}(1,71)=3.99 ; \mathrm{p}=.048\right.$, partial $\left.\eta^{2}=.03, N=72\right]$ and the group $[\mathrm{F}(1,71)$ $=6.30 ; \mathrm{p}=.013$, partial $\left.\eta^{2}=.05, N=72\right]$ with a weak effect strength after Cohen (1992) of $f=.18$ and $f=.23$ on. Similarly, the evaluation found a significant interaction effect between time and group $\left[\mathrm{F}(1,71)=7.87 ; \mathrm{p}=.006\right.$, partial $\eta^{2}=.06, N$ $=72]$, which, with an effect strength $f$ of .26 according to Cohen (1992), corresponds to an average effect. This resulted in the pupils trained in the $E P a N$ program developing more positively $(M=4.79, S D=.94)$ compared to their initial values $(M=4.34, S D=1.02)$, as detailed in Figure 3. For the control group without training in EPaN $(M=4.22, S D=$ 1.01), no significant correlation was calculated, although their affective responsiveness performance improved slightly $(M=4.41, S D=1.12)$ in the posttest. The pretest results here also indicate slightly higher values stemming from differences in sample size and in female test subjects in the intervention group $(M=4.34)$ compared with the control group $(M=4.22)$ (see Schulte-Rüther et al., 2008).

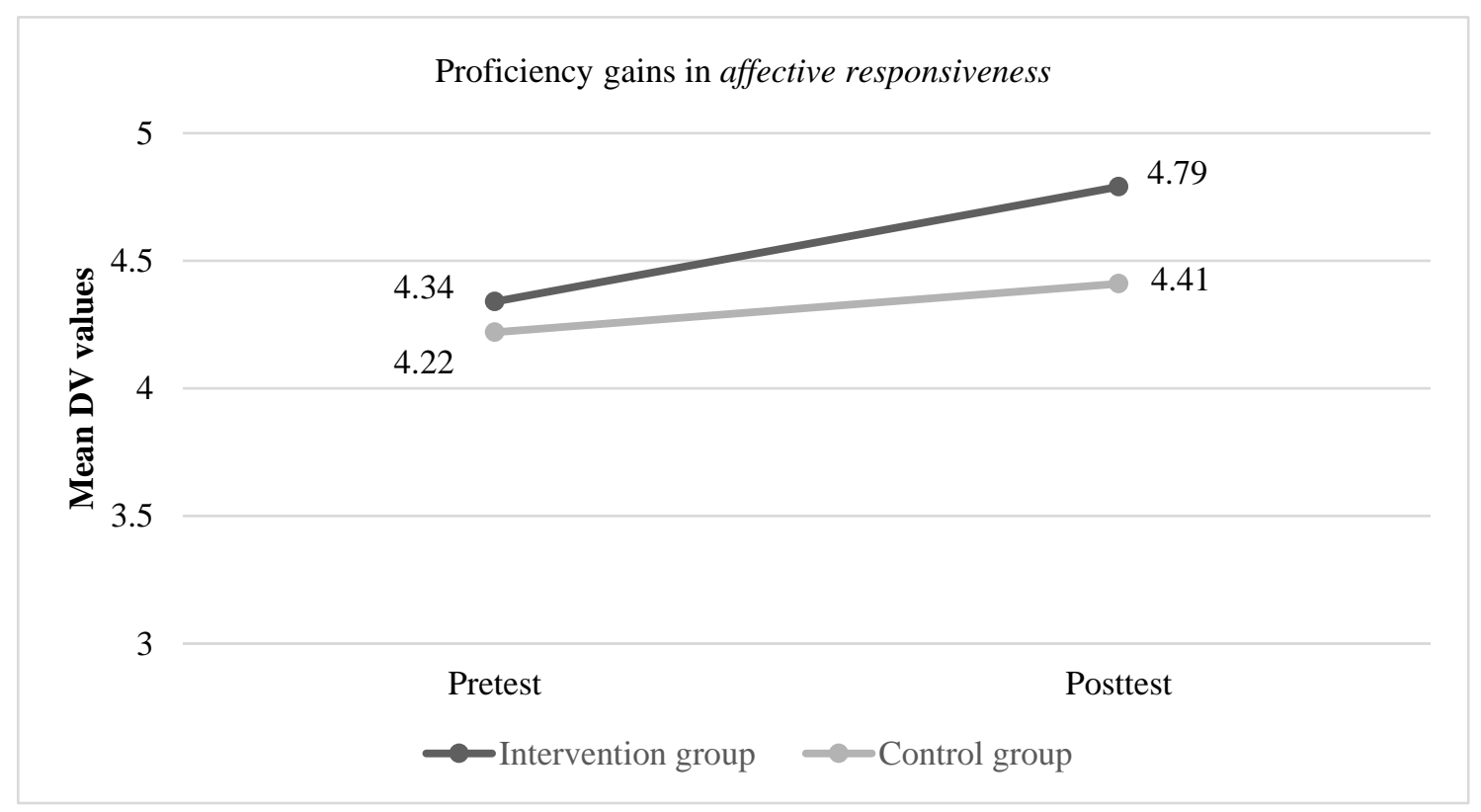

Figure 3. Dependent variable affective responsiveness - differences in proficiency gains of intervention group and control group 


\subsection{Descriptive Findings}

In the final step, evaluation of the trainer surveys conducted during the intervention yielded the following results, based on the trainers having been asked after each completed intervention unit to evaluate four key characteristics (Table 3) of the toolkits on a six-point scale (from $6=$ applies completely to $1=$ does not apply). In the processual evaluation part, structuredness of the method $(M=4.83, S D=.64, n=7)$, teaching of procedural knowledge in terms of the respective goal definitions $(M=5.24, S D=.62, n=7)$, repetitive practicing of specified tasks $(M=4.62, S D=.76, n=7)$ and recipient and target group relevance $(M=4.93, S D=.85, n=7)$ produced high survey values. The educators gave the training method on a six-point scale (from $1=$ very good to $6=$ unsatisfactory) overall best scores $(M=1.52, S D=.51, n$ $=7)$.

Table 3. Mean values (M) and standard deviations (SD) of the toolkit ratings

\begin{tabular}{|c|c|c|c|c|c|c|c|c|c|c|}
\hline & \multirow[t]{3}{*}{ Outcome } & \multicolumn{9}{|c|}{ Training blocks } \\
\hline & & \multicolumn{3}{|c|}{ Toolkit 1} & \multicolumn{3}{|c|}{ Toolkit 2} & \multicolumn{3}{|c|}{ Toolkit 3} \\
\hline & & $M$ & $S D$ & $n$ & $M$ & $S D$ & $n$ & $M$ & $S D$ & $n$ \\
\hline a) & $\begin{array}{l}\text { Structuredness of the } \\
\text { measure }\end{array}$ & 4.93 & .74 & 7 & 4.86 & .69 & 7 & 4.71 & .49 & 7 \\
\hline b) & $\begin{array}{l}\text { Teaching procedural } \\
\text { knowledge }\end{array}$ & 5.29 & .76 & 7 & 5.00 & .58 & 7 & 5.43 & .54 & 7 \\
\hline c) & $\begin{array}{l}\text { Repeated exercise on specific } \\
\text { tasks }\end{array}$ & 4.43 & .87 & 7 & 4.86 & .62 & 7 & 4.57 & .78 & 7 \\
\hline d) & $\begin{array}{l}\text { Relevance of recipients and } \\
\text { target groups }\end{array}$ & 5.07 & .85 & 7 & 5.00 & .90 & 7 & 4.72 & .79 & 7 \\
\hline
\end{tabular}

Notes: Evaluation of key training characteristics on a six-point Likert scale (from $6=$ applies completely to $1=$ does not apply)

\section{Discussion}

4.1 Results

The development of empathic skills not only forms the necessary basis for the soft skills called for by a school's training and education goals (Haep \& Steins, 2016), but in the extracurricular context also indicates an individual's growing capacity to perceive and understand another person's feelings, thoughts and motives and then act on them commensurately. The purpose of the present study was to test the effectiveness of the empathy fostering program (EPaN) that we developed based on the theory by Hirn and colleagues (2018) adjusted for the needs of the current student body in the mainstream public school system.

The significant effects of group $(f=.40)$ and time $(f=.41)$ fundamentally validates differences observed during analysis of the empathy-fostering progress in the intervention and control groups with respect to the empathy components recognition of emotion, emotional perspective taking and affective responsiveness. However, the three dependent variables require separate reflection as follows:

a) An interesting revelation is a significantly increased competence in the empathic sub-capability of recognition of emotions $(f=.52)$ from use of the $E P a N$ recognition of emotions toolkit 1 . After empathy fostering training, the members of the intervention group were much better at identifying and differentiating the positively and negatively valent emotions, as well at distinguishing as simultaneously what triggers like feelings in other people. Therefore, fostering the capability for recognizing emotions seems to be especially important for significantly complementing and modifying cognitive schemes of emotional knowledge already existing in memory (cf. Atkinson and Shiffrin, 1968). It makes the emotional state of the other person more readily accessible, adapts the own elaborated assessment of action more fittingly as the adolescent's performance measure (Hirn et al., 2018), and consequently modulates own behavior to fit situational requirements. This realization is so important because the social context, i.e., the school, triggers a multitude of emotions owing to the dynamics that it gives rise to. If the pupils were not adept before at recognizing and comprehending emotions, this emerged initially in the deficient social behavior particularly in at-risk children and adolescents (Denham et al., 2003).

b) The conspicuous gains in the empathy component emotional perspective taking $(f=.54)$ among students trained with the EPaN perspective taking toolkit 2 is also a result worth discussing in detail. Rapidly growing cognitive developments in adolescence (Demetriou et al., 2002; Dumontheil, 2016) are accompanied by progressive demands for inhibitory 
control as well as working memory requirements of the executive functions whose progress is crucial for successfully processing theory-of-mind tasks (Carlson et al., 2002; Hughes \& Ensor, 2007; Kloo \& Perner, 2003). The prior encoding of social cues in facial expression, gesticulation, and posture thus brought about - besides the attribution of the interaction partner's intentions - a more conscious realization of emotional perspective taking by the pupils as they concentrated on the individual exercises. Growing awareness of forming alternative courses of action and the consequences of decision making also appears vital for realizing that different people draw different conclusions and that they consequently model differing outcomes. In fact, the intervention's goal of increasing emotional perspective taking generally takes a backseat among youngsters more interested in a decidedly active use of the capacity for emotional perspective taking in real-life confrontational situations (Gutzwiller-Helfenfinger, 2016). The results seem to dovetail with relevant studies which showed that, in addition to the positive reciprocal relationship between theory of mind (ToM) competence and school performance (Astington \& Pelletier, 2005), also correlated were young people's understanding of mental states and their peer-validated social competence (Bosacki \& Astington, 1999). Gains in the empathic components and trained knowledge about them could also have a lasting positive effect by dynamically changing aggressive behavior and victimization in the subgroup of disadvantaged adolescents (Yanagida et al., 2019). Fostering emotional perspective taking in the school environment fundamentally influences the mutual development of interpersonal relationships even if one individual opts for an alternative action that is destined to be the wrong one.

c) Also evident in the present study are significant gains in the empathy component affective responsiveness $(f=.26)$ in EPaN responsiveness toolkit 3. Distinct relationships between the affective responsiveness empathy component and the cognitive empathy component of emotional perspective taking were thoroughly documented by Hirn and colleagues (2018). Not to be ruled out therefore is the positive supportive function of both mutually-influencing components in increasing the understanding of behaviors and mental states of others in the test subjects from doing the specialized exercises of the empathy fostering method. Awareness first draws attention to inner workings in becoming conscious of the self, with all its natural predispositions, and in differentiating individual emotional processes. Only then does an extension of what is learned through subsequent exercises become indicatory for young people, namely by applying what is known about things and happenings in the environment (others) in the same way to contacts with individuals or groups (Abram \& Hirzel, 2010; Stevens, 1975). If the trainees are increasingly able to separate - or structure a separate awareness of - their own emotional states (self) from those of others (Decety \& Jackson, 2004), they are also much more likely to make decisions that expand rather than narrow the scope for action in social interactions. It can be assumed that the exercises are perfectly capable of contributing to affective responsiveness with respect to perceiving the self as separate from the others.

Notably, the contents from the toolkit 3 exercises themselves, in addition to the positive inputs from recognition of emotions and emotional perspective taking, should by no means be overlooked with respect to gains achieved in the empathy component affective responsiveness thanks to increased skill acquisition by the youngsters, bound in situationally required arrangements to participate in each case in the special education practices (Schäffter, 2009). Skill building is often supported in the exercises of toolkit 3 by functionally didacticised learning arrangements that provide opportunities for acquiring new knowledge, but also for practicing unfamiliar skills and abilities. Moreover, they can be customized by the individual (Schäffter, 2009). The very process of learning, which starts with simply participating, thus creates suitable learning opportunities for each individual and, conversely, boosts intrapersonal affective responsiveness. However, in the educational context, a complete assessment during observation or training proves to be extremely difficult for groups that are often disadvantaged.

Indeed, the individual special education arrangements of each of the affective responsiveness exercises at times turn out to be decisive for significant educational effects on skill acquisition, in addition to the importance of the strongly mutuallyrelated variables of recognition of emotion and emotional perspective taking for affective responsiveness. It therefore stands to reason that already stored schemas and knowledge structures in the intervention participant database (Crick \& Dodge, 1994, Thomas et al., 2006) through prior exercises were subjected to a quasi-review and reorganization of desired action goals (Kubesch \& Walk, 2009).

\subsection{Importance for Pedagogical Practice}

Early class-level fostering methods of reducing risk factors require a stable implementation and feasibility of substantive fostering methods for the interacting empathy components. The key training characteristics garnered from the intervention-accompanying surveys shed light on the basic success criteria for learning with the EPaN program:

a) The structuredness of the method is based on the training schemes having a transparent structure (Forman \& Barakat, 2011), containing an exact description of the competence objectives, giving instructions for the selection of materials, proposing a time frame, containing a canned process with formulated concrete statements on implementation, providing a repertoire of pupil-tested reflection methods and even furnishing guidance on how to carry them out in the case of high- 
risk participants or groups. In addition, the exercises are fully elaborated for the implementers in tabular, manual and digital form, which, compared to highly elaborated programs, makes them more adaptable to the current needs of the class or school and facilitates the integration of content in individual subjects.

b) Another qualificatory feature concerns the content perspective in transferring procedural knowledge. This poses the question of what will be improved by the program (Fries \& Souvignier, 2015):

The exercises from the recognition of emotion toolkit 1 at their core strengthen understanding of pleasant and unpleasant emotional states reflected in one's own facial expressions, gesticulation and posture and in those of others. Indeed, emotions constitute a relevant form of expression and decision-making basis for a successful interaction, which allows predicting the future behavior of interaction partners (Rau \& Pauli, 2004). Proficiency in recognizing the basic emotions varies, with grief and anxiety more difficult to identify than joy or anger (Ekman 1988; 2004; Izard, 1994; Tracy \& Robins, 2008).

Toolkit 2 for emotional perspectives taking contentwise adheres to the importance of distinguishing between one's own and the generalized perspective. A young person is taught through targeted exercises to put himself increasingly into the other's shoes but also to look at himself through the other's eyes before deciding on a specific behavior (GutzwillerHelfenfinger, 2016). In terms of a cognitive theory of mind (ToM), this fosters understanding of one's own and another's mental state, by which is meant what we know, want, think and feel (Meinhardt, Sodian, Thoermer, Döhnel, \& Sommer, 2011).

The content of the third tool kit for affective responsiveness is designed in a way that lets the participants, through targeted practical exercise techniques, separate the emotional state of the counterpart and their own state in the sense of a selfother awareness (Decety \& Jackson, 2004). Here, the choice of a method from gestalt techniques and role-playing games is particularly suited for increasing an affectively-based understanding among young people (Calley \& Gerber, 2008; Pearson, Russ, \& Cain Spannagel, 2008). The methods' aim is to become more self-aware, to know oneself better, to deepen internal processes and to expand contacts with interaction partners and events in the environment (Stevens, 1975; Abram \& Hirzel, 2010).

c) Through repetition of specific tasks, the program also supports another key feature. The program is really built around an internal microstructure of the exercises, which do not necessarily follow a curricular structure. Moreover, there is always the option of repeating individual exercises in depth independently of each other. In some sub-areas preexist variations that are available for individualizing phases to permit internal differentiation. Several additional elements can be selected from the material pool (varying image and presentation material, student reflection methods) at any time to assess the exercise relevance in the group and ensure the possibility of repeated and in-depth automation processes. We largely dispensed with the exclusive use of worksheets and unnecessary text specifications for the participants with an eye to preserving the variety and fun of the units through an activity-oriented character.

d) To maintain the relevance of the recipients and target groups, the exercises are fashioned for small groups as well as an entire class. Existing individual resources are bundled within a group. This counters the risk of stigmatization processes through the potential singling-out of high-risk young people (Goffman, 2007). Using peer-based methods, the program encompasses learning from models (Bandura, 1965) as an important factor in the social and emotional development of youngsters. Since the importance of methodological variety has been proved scientifically in multiple studies (Hattie, Beywl, \& Zierer, 2013), the choice focuses primarily on active, problem-solving methods, with the added elements of letting the children and youths take responsibility and design work phases themselves. The program concept also focuses on language that is appropriate for the training recipients, on an appropriate didactic reduction of complex content, as well as on a transfer to realistic situations in the reflection phases by asking specific questions.

\subsection{Limitations and Perspectives}

From the analyzed object emerge several limitation of the results.

Significant intervention effects of the empathy components recognition of emotion, emotional perspective taking and affective responsiveness do indicate in a before-and-after comparison that the EPaN program is effective. However, since we lack follow-up surveys owing to school organization and transfers, the results only allow us to make conditional statements as to their stability over time.

The young people studied are also a selective sample in which mainstream public school pupils from low to medium socioeconomic backgrounds are overrepresented. Implementation in primary or secondary schools with corresponding optimizations and changes to individual training sessions merit further investigation.

Nevertheless, the present results provide supporting evidence for a motivational empathy training program that makes allowances for newer competence-oriented teaching methods in the mainstream public school sector. Should the program over a longer period of time be adopted in a targeted manner early on in the entry classes as an upstream measure, it could 
not only sustainably equip children and young people for subsequent intervention programs, but also be integrated into the development activities of many educational institutions with respect to social learning.

\section{References}

Abram, A., \& Hirzel, D. (2010). Fühlen erwünscht. Praxishandbuch für alle sozialen Berufe. Mit 88 Übungen für verschiedene Zielgruppen und Symptomatiken. Paderborn: Junfermann Verlag.

Adolphs, R., \& Damasio, A. R. (2000). Neurobiology of emotion at a system level. In J.A. Borod (Ed.), The Neuropsychology of emotion. Oxford: University Press.

Astington, J. W., \& Pelletier, J. (2005). Theory of mind, language, and learning in the early years: Developmental origins of school readiness. In B. D. Homer \& C. S. Tamis-LeMonda (Hrsg.), The development of social cognition and communication, 205-230. Mahwah, NJ: Lawrence Erlbaum.

Atkinson, R. C., \& Shiffrin, R. M. (1968). Human memory: A proposed system and its control processes. In K. W. Spence \& J. T. Spence (Hrsg.), The psychology of learning and motivation, 90-197. London: Academic Press. https://doi.org/10.1016/S0079-7421(08)60422-3

Bandura, A. (1965). Influence of models` reinforcement contingencies on the acquisition of imitative responses. Journal of Personality and Social Psychology, 1, 589-595. https://doi.org/10.1037/h0022070

Berghofer, G., Gonja, T., \& Oberlechner, T. (2008). Kann Empathie trainiert werden? Ein Review empirischer Studien zur Wirksamkeit von Empathietraining. Person, 2, 33-48.

Bosacki, S., \& Astington, W. J. (1999). Theory of mind in preadolescence: Relations between social understanding und social competence. Social Development, 8, 237-255. https://doi.org/10.1111/1467-9507.00093

Brattig, V. (2013). Inklusion statt Integration junger Menschen mit vorrangig psychischen Problemen in der beruflichen Rehabilitation? In Berufliche Rehabilitation, Beiträge zur beruflichen und sozialen Teilhabe junger Menschen mit Behinderung. Schwerpunktthema: Inklusion IV, 27(1), 31-48.

Calley, N. C., \& Gerber, S. (2008). Empathy-promoting counseling strategies for juvenile sex offenders: A developmental approach. Journal of Addictions \& Sexual Counseling, 28, 68-85. https://doi.org/10.1002/j.21611874.2008.tb00034.x

Carlson, S. M., Moses, L. J., \& Breton, C. (2002). How specific is the relation between executive function and theory of mind? Contributions of inhibitory control and working memory. Infant Child Development, 11(2), 73-92. https://doi.org/10.1002/icd.298

Cierpka, M. (2011). FAUSTLOS - Wie Kinder Konflikte gewaltfrei lösen lernen. Freiburg im Breisgau: Herder Verlag.

Cohen, J. (1992). A power primer. Psychological Bulletin, 112(1), 155-159. https://doi.org/10.1037/0033-2909.112.1.155

Crick, N. R., \& Dodge, K. A. (1994). A review and reformulation of social information processing mechanisms in children's social adjustment. Psychological Bulletin, 115(1), 74-101. https://doi.org/10.1037/0033-2909.115.1.74

Decety, J., \& Jackson, P. L. (2006). A social-neuroscience perspective on empathy. Current directions in psychological science, 15(2), 54-58. https://doi.org/10.1111/j.0963-7214.2006.00406.x

Decety, J., \& Jackson, P. L., (2004). The functional architecture of human empathy. Behavioral and cognitive neuroscience reviews, 3(2), 71-100. https://doi.org/10.1177/1534582304267187

Decety, J., \& Lamm C. (2006). Human empathy through the lens of social neuroscience. Scientific World Journal, 6, 1146-1163. https://doi.org/10.1100/tsw.2006.221

Demetriou, A., Christou, C., Spanoudis, G., \& Platsidou, M. (2002). The development of mental processing: efficiency, working memory and thinking. Monographs of the Society for Research in Child Development, 67(1). https://doi.org/10.1111/1540-5834.671177

Denham, S. A., Blair, K., DeMulder, E., Levitas, J., Sawyer, K., Auerbach-Major, S., \& Queenan, P. (2003). Preschool emotional competence: Pathway to social competence. Child Development, 74, 238-256. https://doi.org/10.1111/1467-8624.00533

Derntl, B., Finkelmeyer, A., Eickhoff, S., Kellermann, T., Falkenberg, D., Schneider, F., \& Habel, U. (2010). Multidimensional assessment of empathic abilities: Neural correlates and gender differences. Psychoneuroendocrinology, 35(1), 67-82. https://doi.org/10.1016/j.psyneuen.2009.10.006

Derntl, B., Finkelmeyer, A., Toygar, T., Hülsmann, A., Schneider, F., \& Falkenberg, D. (2009). Generalized deficit in all core components of empathy in schizophrenia. Schizophrenia Research, 108, 197-206. 
https://doi.org/10.1016/j.schres.2008.11.009

Derntl, B., Kryspin-Exner, I., Fernbach, E. M., Moser, E., \& Habel, U. (2008b). Emotion recognition accuracy in healthy young females is accociated with cycle phase. Horm. Behav., 53(1), 90-95. https://doi.org/10.1016/j.yhbeh.2007.09.006

Derntl, B., Windischberger, C., Robinson, S., Lamplmayr, E., Kryspin-Exner, I., Gur, R. C., ... Habel, U. (2008a). Facial emotion recognition and amygdala activation are associated with menstrual cycle phase. Psychoneuroendocrinology 33(8), 1031-1041. https://doi.org/10.1016/j.psyneuen.2008.04.014

Döpfner, M. (1989). Social information processing: A contribution to the differentiation of social incompetence. German Journal of Educational Psychology, 3(1), 1-8.

Dumontheil, I. (2016). Adolescent brain development. Current Opinion in Behavioral Sciences, 10, 39-44. https://doi.org/10.1016/j.cobeha.2016.04.012

Eisenberg, N. (2000). Emotion, regulation, and moral development. Annual Review of Psychology, 51, 665-697. https://doi.org/10.1146/annurev.psych.51.1.665

Eisenberg, N., \& Miller, P. A. (1987). The relation of empathy to prosocial and related behaviors. Psychological Bulletin, 3(1), 91-119. https://doi.org/10.1037/0033-2909.101.1.91

Ekman, P. (1988). Gesichtsausdruck und Gefühl: 20 Jahre Forschung von Paul Ekman. Paderborn: Junfermann.

Ekman, P. (2004). Gefühle lesen: Wie sie Emotionen erkennen und richtig interpretieren. Heidelberg: Elsevier.

Elias, M. J. (2006). The connection between academic and social-emotional learning. In M. J. Elias \& H. Arnold (Hrsg.), The educator's guide to emotional intelligence academic achievement, 4-14, Thousand Oaks, CA: Corwin Press.

Fath, K. (2011). Der Psychologische Dienst in Berufsbildungswerken-wirksame und wesentliche Instanz. In Berufliche Rehabilitation, 2, 78-90.

Fitzgerald, D. A., Angstadt, M., Jelsone, L. M., Nathan, P. J., \& Phan, K. L. (2006). Beyond threat: amygdala reactivity across multiple expressions of facial affect. NeuroImage 30(4), 1441-1448. https://doi.org/10.1016/j.neuroimage.2005.11.003

Forman, S. G., \& Barakat, N. M. (2011). Cognitive-behavioral therapy in the schools: bringing research to practice through effective implementation. Psychology in the Schools, 48(3), 283-296. https://doi.org/10.1002/pits.20547

Fries, S., \& Souvignier, E. (2015). Training. In E. Wild \& J. Möller (Hrsg.). Pädagogische Psychologie, 2nd ed., 402-404. Berlin Heidelberg: Springer Verlag. https://doi.org/10.1007/978-3-642-41291-2_17

Goffman, E. (2007). Stigma: Über Techniken der Bewältigung beschädigter Identität, 13th ed.. Frankfurt am Main: Suhrkamp.

Gur, R. C., Radim, S., Hagendoorn, M., Marom, O., Hughett, P., Macy, L., ... Gur, R. E. (2002). A method for obtaining 3-dimensional facial expressions and its standardization for use in neurocognitive studies. J. Neurosci. Methods, 115(2), 137-143. https://doi.org/10.1016/S0165-0270(02)00006-7

Gutzwiller-Helfenfinger, E. (2016). Die Wirkung von erweitertem Rollenspiel auf soziale Perspektivenübernahme und antisoziales Verhalten. In T. Malti \& S. Perren (Hrsg.), Soziale Kompetenz bei Kindern und Jugendlichen. Entwicklungsprozesse und Fördermöglichkeiten, 2nd ed., 244-261. Stuttgart: W. Kohlhammer Verlag

Habel, U., Windischberger, C., Derntl, B., Robinson, S., Kryspin-Exner, I., Gur, R. C., \& Moser, E. (2007). Amygdala activation and facial expressions: explicit emotion discrimination versus implicit emotion processing. Neuropsychologia 45(10), 2369-2377. https://doi.org/10.1016/j.neuropsychologia.2007.01.023

Haep, A., \& Steins, G. (2016). Soziales Lernen in der Schule. In M. Roth, V. Schönefeld, \& Tobias Altmann (Hrsg.), Trainings- und Interventionsprogramme zur Förderung von Empathie. Ein praxisorientiertes Kompendium, 25-39. Berlin und Heidelberg: Springer Verlag. https://doi.org/10.1007/978-3-662-48199-8_3

Haep, A., Steins, G., \& Wilde, J. (2014). Soziales Lernen Sekundarstufe I, 2nd ed.. Donauwörth: Auer. https://doi.org/10.1007/978-3-662-48199-8_3

Hall, J. A., \& Matsumoto, D. (2004). Gender differences in judgements of multiple emotions from facial expressions. Emotion, 4, 201-206. https://doi.org/10.1037/1528-3542.4.2.201

Hall, J. A., \& Matsumoto, D. (2004). Gender differences in judgements of multiple emotions from facial expressions. Emotion, 4, 201-206. https://doi.org/10.1037/1528-3542.4.2.201

Hattie, J., Beywl, W., \& Zierer, K. (2013). Lernen sichtbar machen. Baltmannsweiler: Schneider Verlag Hohengehren. 
Haynes, L. A., \& Avery, A. W. (1979). Training adolescents in self-disclosure and empathy skills. Journal of Counseling Psychology, 26(6), 526-530. https://doi.org/10.1037/0022-0167.26.6.526

Hinsch, R., \& Pfingsten U. (2015). Gruppentraining sozialer Kompetenzen (GSK). Grundlagen, Durchführung, Anwendungsbeispiele, 6th ed.. Weinheim: Beltz PVU.

Hirn, S. L., Thomas, J., \& Zoelch, C. (2018). The role of empathy in the development of social competene: A study of German school leavers. International Journal of Adolescence and Youth, 23(4), 1-14. https://doi.org/10.1080/02673843.2018.1548361

Hughes, C., \& Ensor, R. (2007). Executive function and Theory of Mind: predictive relations from ages 2 to 4. Developmental Psychology, 43(6), 1447-1459. https://doi.org/10.1037/0012-1649.43.6.1447

Izard, C. E. (1994). Die Emotionen des Menschen. Eine Einführung in die Grundlagen der Emotionspsychologie. Weinheim: Beltz.

Kipper, D. A., \& Ben-Ely, Z. (1979). The effectiveness of the psychodramatic double method, the reflection method, and lecturing in the training of empathy. Journal of Clinical Psychology, 35(2), 370-375. https://doi.org/10.1002/10974679(197904)35:2<370::AID-JCLP2270350229>3.0.CO;2-Y

Kloo D., \& Perner J. (2003). Training transfer between card sorting and false belief understanding: helping children apply conflicting descriptions. Child Development, 74(6), 1823-1839. https://doi.org/10.1046/j.1467-8624.2003.00640.x

Kubesch, S., \& Walk, L. (2009). Körperliches und kognitives Training exekutiver Funktionen in Kindergarten und Schule. In Sportwissenschaft (4), 309-317. Springer Medizin Verlag. https://doi.org/10.1007/s12662-009-0079-2

Lemerise, E. A., \& Arsenio, W. F. (2000). An integrated model of emotion processes and cognition in social information processing. Child Development, 71, 107-118. https://doi.org/10.1111/1467-8624.00124

Maier, G. W., \& Rappensperger, G. (1999). Eintritt, Verbleib und Aufstieg in Organisationen. In C. Graf Hoyos \& D. Frey (Hrsg.), Arbeits- und Organisationspsychologie. Ein Lehrbuch, 50-63. Weinheim: Beltz PVU.

Manger, T., Eikeland, O.-J., \& Asbjornsen, A. (2001). Effects of social-cognitive training on students' empathy. Swiss Journal of Psychology/Schweizerische Zeitschrift für Psychologie/Revue Suisse de Psychologie, 60(2), 82-88.

McMahon, S. D., \& Washburn, J. (2003). Violence prevention: An evaluation of program effects with urban African American students. The Journal of Primary Prevention, 24(1), 43-62. https://doi.org/10.1023/A:1025075617356

Meinhardt, J., Sodian, B., Thoermer, C. Döhnel, K., \& Sommer, M. (2011). True- and false belief reasoning in children and adults: An event-related potential study of theory of mind. Developmental Cognitive Neuroscience, 1, 67-76. https://doi.org/10.1016/j.den.2010.08.001

Moser, E., Derntl, B., Robinson, S., Fink, B., Gur, R. C., \& Grammer, K. (2007). Amygdala activation at 3 T in response to human and avatar facial expressions of emotions. J. Neurosci. Methods 161(1), 126-133. https://doi.org/10.1016/j.jneumeth.2006.10.016

Nerdrum, P., \& Ronnestad, M. H. (2003). Changes in therapists' conceptualization and practice of therapy following empathy training. Clinical Supervisor, 22(2), 37-61. https://doi.org/10.1300/J001v22n02_04

Paciello, M., Fida, R., Cerniglia, L., Tramontano, C., \& Cole, E. (2013). High cost helping scenario: The role of empathy, prosocial reasoning and moral disengagement on helping behavior. Personality and Individual Differences, 55, 3-7. https://doi.org/10.1016/j.paid.2012.11.004

Pawelak, U. (2004). Kurzform der ,,Vienna Emotion Recognition Tasks “(VERT-K) und der Vienna Memory of Emotion Recognition Tasks “ (VIENNER-K). Unveröffentlichte Diplomarbeit, Universität Wien.

Pearson, B. L., Russ, S. W., \& Cain Spannagel, S. A. (2008). Pretend play and positive psychology: Natural companions. Journal of Positive Psychology, 3(2), 110-119. https://doi.org/10.1080/17439760701760617

Pecukonis, E. V. (1990). A cognitive/affective empathy training program as a function of ego development in aggressive adolescent females. Adolescence, 25(97), 59-76.

Rau, H., \& Pauli, P. (2004). Medizinische Psychologie, Medizinische Soziologie systematisch, 2. Bremen: UNI-MED.

Roth, M., Schönefeld, V., \& Altmann, T. (2016). Einleitung: Definitionen, Modelle und Trainierbarkeit von Empathie. In M. Roth, V. Schönefeld, \& T. Altmann (Eds.), Trainings- und Interventionsprogramme zur Förderung von Empathie. Ein praxisorientiertes Kompendium, 1-9. Berlin und Heidelberg: Springer-Verlag. https://doi.org/10.1007/978-3662-48199-8_1

Schäffter, O. (2009). Lernen - ein Grundbegriff pädagogischer Praxis. In A. Mörchen \& M. Tolksdorf (Hrsg.), Lernort 
Gemeinde. Ein neues Format der Erwachsenenbildung, 89-102, Bielefeld: Bertelsmann Verlag.

Schulte-Rüther, M., Markowitsch, H. J., Shah, N. J., Fink, G. R., \& Piefke, M. (2008). Gender differences in brain networks supporting empathy. NeuroImage, 42, 393-403. https://doi.org/10.1016/j.neuroimage.2008.04.180

Schultze-Krumbholz, A., Zagorscak, P., Wölfer, R., \& Scheithauer, H. (2014). Das Medienhelden-Programm zur Förderung von Medienkompetenz und Prävention von Cybermobbing: Konzept und Ergebnisse aus der Evaluation. Praxis der Kinderpsychologie und Kinderpsychiatrie, 63, 379-394. https://doi.org/10.13109/prkk.2014.63.5.379

Shamay-Tsoory, S. G. (2009). Empathic processing: its cognitive and affective dimensions and neuroanatomical basis. In J. Decety, J. \& Ickes, W. (Eds.), The social neuroscience of empathy, 215-232. Cambridge, UK: A Bradford Book. The MIT Press. https://doi.org/10.7551/mitpress/9780262012973.003.0017

Stevens, J. O. (1975). Die Kunst der Wahrnehmung. Übungen der Gestalttherapie. München: Chr. Kaiser Verlag.

Strayer, J., \& Roberts, W. (2004). Empathy and observed anger and aggression in five-year-olds. Social Development, 13, 1-13. https://doi.org/10.1111/j.1467-9507.2004.00254.x

Thomas, J., Jänsch, A., \& Niedermaier, A. (2006). Förderdiagnostik sozialer Kompetenzen bei benachteiligten Jugendlichen - Entwicklung eines videobasierten Diagnoseinstrumentes. Jugend, Beruf, Gesellschaft, 57, $180-189$.

Tracy, J. L., \& Robins, R. W. (2008). The automaticity of emotion recognition. Emotion, 8(1), 81-95. https://doi.org/10.1037/1528-3542.8.1.81

Vasallo, S, Cooper, S. L., \& Douglas, J. M. (2009). Visual scanning in the recognition of facial affect: is there an observer sex difference? Journal of Vision, 9(3), 11, 1-10. https://doi.org/10.1167/9.3.11

Yanagida, T., Strohmeier, D., \& Spiel, C. (2019). Dynamic change of aggressive behavior and victimization among adolescents: Effectiveness of the ViSC program. Journal of Clinical Child \& Adolescent Psychology, 48(1), 90-104. https://doi.org/10.1080/15374416.2016.1233498

\section{Copyrights}

Copyright for this article is retained by the author(s), with first publication rights granted to the journal.

This is an open-access article distributed under the terms and conditions of the Creative Commons Attribution license which permits unrestricted use, distribution, and reproduction in any medium, provided the original work is properly cited. 